DOI: $10.20472 /$ IAC.2019.049.030

\title{
MUJO MESANOVIC
}

American University of Sharjah, United Arab Emirates

\section{THE STATISTICS ONLINE CLASS}

\begin{abstract}
:
Technology is a norm in today's life, particularly in higher education. Incorporating technology and technological tools in higher education has a wide range of applications, and people are trying to integrate them within teaching and learning. Two of the main challenges that people face are individual technological skills and cost associated with the use of technology. The aim of this presentation is to show how faculty with minimal technological skills and no financial cost could be able to create an online class. Through this talk broad explanation about available online resources will be discussed. Also, the pilot project (case study) about online class in statistic from American University of Sharjah will be presented with results indicating a successful implementation.
\end{abstract}

\section{Keywords:}

technology, online class, cost free

JEL Classification: 123,129 